\title{
How Probes Work
}

\author{
Connor Graham ${ }^{1}$, Mark Rouncefield ${ }^{1}$, Martin Gibbs ${ }^{2}$, Frank Vetere ${ }^{2}$ and Keith Cheverst ${ }^{1}$ \\ ${ }^{1}$ Computing Department, Lancaster University \\ Infolab21, South Drive, Lancaster LA1 4WA \\ United Kingdom \\ ${ }^{2}$ Dept of Information Systems, University of Melbourne \\ Parkville, Victoria 3010 \\ Australia \\ \{c.graham\}\{m.rouncefield\}@lancaster.ac.uk, \{martin.gibbs\}\{fv\}@unimelb.edu.au, \\ kc@comp.lancs.ac.uk
}

\begin{abstract}
'Cultural probes', since first being proposed and described by Bill Gaver and his colleagues, have been adapted and appropriated for a range of purposes within a variety of technology projects. In this paper we critically review different uses of Probes and discuss common aspects of different Probe variants. We also present and critique some of the debate around Probes through describing the detail of their use in two studies: The Digital Care Project (Lancaster University) and The Mediating Intimacy Project (University of Melbourne). We then reorient the discussion around Probes towards how probes work: both as interpretative fodder for social scientists and as a resource for 'designers'. Finally we discuss new possible directions for Probes as an approach and some of the challenges confronting Probes as an approach.
\end{abstract}

\section{Categories and Subject Descriptors}

H.5.2 [Information Interfaces and Presentation (e.g. HCI)]: User Interfaces - theory and methods, user-centred design; Miscellaneous

\section{General Terms}

Design, Human Factors

\section{Keywords}

Cultural Probes, Design Process

\section{INTRODUCTION}

"Learn from me, if not by my precepts, at least by my example..." (Dr Frankenstein in [32])

The turn to social science disciplines [17] in HCI was an attempt to elicit and provide meaningful, design relevant insights into users, their behaviours and use of technologies. This has inevitably embraced the accompanying methods for investigating aspects of social life. Different approaches have had periods of popularity and development in HCI ethnography for example (e.g. [19], [6]) and, in recent years the idea of "Cultural probes" (e.g. [10]) whereby, to some at least, it appeared that perhaps $\mathrm{HCI}$ had, at last, found a method (if not a methodology) all of in their own, a method rooted in the

OzCHI 2007, 28-30 November 2007, Adelaide, Australia. Copyright the author(s) and CHISIG. Additional copies are available at the ACM Digital Library (http://portal.acm.org/dl.cfm) or can be ordered from CHISIG(secretary@ chisig.org)

OzCHI 2007 Proceedings, ISBN 978-1-59593-872-5 social, that involved users in various ways and that seemed to lead to serious, relevant design recommendations and serious, relevant designs.

Indeed, the significance of Probes as an approach has not gone unnoticed by those critiquing trends in HCI. For instance, Boehner and her colleagues [1], in their analysis of Probes as an approach within HCI state that:

"Our goal in this paper is not to analyze the problems and potentials of probes per se, nor to set out a critique of the ways in which the approach has been taken up in different projects... what we want to look at is the reason why probes have been taken up broadly, and in the ways in which they have."

Here we attempt 'something completely different'. Whilst we have a normal, everyday curiosity, we are not really or especially interested in researchers' motivation - in 'why probes have been taken up'. However, we do believe that key questions remain unanswered; questions concerning how Probes work both as a means of engaging and provoking responses from participants and as a resource for those involved in design i.e. creative designers, computer scientists, engineers, ethnographers and so on. Addressing these, albeit very practical, questions is not an attempt to circumvent methodological concerns: we believe that the everyday, common (if fragmentary) detail of methods being enacted in projects (through, for example, describing how probe data was interpreted) actually makes visible underlying methodological commitments, commitments that are accountable [8]. We also believe that it is extremely difficult to speculate regarding reasons for appropriation of any methodological approach without reference to real data. Thus in this paper we not only critically (and hopefully carefully) review others' Probe deployments through at times extensively quoting from their work, but also draw on two cases of Probe deployments in which we have been involved. We don't believe the latter to be an over-zealous commitment to our own work; examining what actually happened, some of the problems encountered, and some of the unexpected results is a useful approach given the question we aim to answer in this paper. In addressing it, we hope to dispel some of the mystique that cloaks Probes and design, for, like Dr Frankenstein we seek to learn by example, from the 'monster' we, at least in part, helped to create.

\section{SOME INITIAL CONCERNS}

The notion of a 'probe' can refer to a number of things - and all of these versions, or aspects of them, can and have appeared in HCI research. Robotic probes, for example, are devices that gather information from remote, hazardous or difficult 
locations. Probes may return their data over radio links or be physically tethered to controllers. Examples of these include the Voyager space probes - that included, on a gold phonograph record, details about Earth and its various languages, animals, civilizations, and arts and an invitation to come visit. Probe is also used to describe surgical instruments that allow doctors to see inside the body. In the Social Sciences and particularly in social surveys, a probe is an attempt to elicit a deeper or more enlightening response to a question

In considering how Probes work and how they become a resource for 'designers' it seems important to consider the implications of them being converged upon by multiple disciplines - engineering, design, social science and ethnography. Thus, it is somewhat inevitable that there will be very different stances in any debate around Probes.

A key point to make here is that Probes have been operating across different "communities of practice" [37] with different vocabularies, practices and notions of rigour. These communities often have different ideas of what 'design' actually is and who does it. Vetting Wolf and her colleagues [36], as well as Jonas Löwgren [22] (who they quote), support this assertion, distinguishing between "engineering design" and "creative design". Engineering design is formalised, 'objective' and often defined in lexical terms whereas creative design explores a 'design space' through subjective involvement by the designer and "a tight interplay between problem setting and problem solving" [22] often through the use of real artefacts such as sketches and models. Vetting Wolf and her colleagues [36] also describe how both schools of design involve rigour and that rigour in creative design is "a repeatable process, of a consensual standard of quality, in use by a professional community of practice." Accordingly, engineering designers may well tend to favour formal use of Probes within a defined, often heavily documented, process with definite outcomes or deliverables and creative designers may tend to favour less measured (but equally delivery oriented) uses of Probes to help develop solutions (as well as set problems) that can be worked through using well established design techniques in their community (e.g. sketching, modelling etc.).

Similarly, Probes have been deployed across communities that have very different ideas concerning interpretation of what Probes produce. Ethnographers (and ethnomethodologists in particular) dismiss the value of generating "abstract, decontextualised models" from Probe data [7] and instead stress the important insights Probes offer for understanding the member's point of view, people's "world within reach" [30]. Other social scientists promote the need to generate models and constituent themes from Probe data in order to promote understanding of difficult, slippery phenomena (e.g. [34]). Bill Gaver, in his commitment to provoke through design, values the "undermining of certainty" (Gaver, personal communication):

"Our interpretations are constantly challenged: by the returns themselves, by the differing interpretations of colleagues, by our own changing perceptions." [14]

However, there are clearly aspects of Probes that are globally comprehensible as part of a stable 'language game' [38] - how else can we talk about them and know what we mean when we do? Despite the exaggerated, binary oppositions that regularly feature in the discussion of Probes - between 'information' and 'inspiration', 'requirements' and 'ludic pursuits' and so on there is much 'common ground' in the deployment of probes in HCI research. So rather than emphasising the (lack of) methodological commitments and intentions of Probe deployments, which we can only be speculative about unless we have any data or experience, we prefer to begin with some aspects of Probes that are generally common across deployments. We draw on many studies using different kinds of probes: Cultural Probes ([9],[10],[11],[12],[13],[14]); Informational Probes [7]; Technology Probes [4],[21]; Mobile Probes [20]; Empathy Probes ([24],[18]); Domestic Probes ([22],[34]); and even Urban Probes [26]. Although clearly not as complete a treatment of work in the space as earlier reviews (e.g. [1]), - at least in terms of raw numbers - we supplement this critical and appreciative review with our own experiences of Probe deployments in order to explore the fundamental question: how probes 'work'.

\subsection{The Common}

"We came up with the idea of packages of evocative materials, then came up with the term 'probes'. It was one of those moments where everything - the approach, ideas for implementation, the name - all clicked into place...Anyway, the name seemed right because it made multiple, simultaneous references:- to space probes returning data over time from far away- to medical probes poking into intimate nooks and crannies- to probes as devices to provoke reactions." [Gaver, personal communication]

The following is a list of features of probes that, at least in the papers we examined, appear common across deployments. Through being held in common they highlight a minimal list of aspects that are broadly, and uncontroversially, indicative of how probes work.

\subsubsection{Capture artefacts}

All Probes include some form of capture device and are used for 'data collection'. Notably, this does not simply involve probes having "material form" [1] but having a particular, often deliberate, (sets of accumulated) affordance(s): a repackaged digital memo-taker enabling participants to describe a vivid dream upon waking [10]; stickers of cartoon faces and other illustrations to support humorous, emotional responses [24]; Polaroid cameras for taking photos of participants' own rooms, friends, visitors and other 'important' things; hand-written, addressed and stamped postcards [26]; a messaging technology allowing logging of communication using digital PostIt notes [21]. These 'capture artefacts' were all carefully constructed in some way to evoke particular responses from participants even with Technology Probes the affordances are particular and responses are provoked through interactions with the artefact.

\subsection{2 (Auto)biographical accounts}

Probes generate accounts of people's individual lives. Indeed, this is commonly seen as one of their strengths. The precise emphasis of these accounts may vary, but they are accounts nonetheless. As Gaver et al. note [14] when discussing the role of probes with regard to their participants:

“...the Probes encouraged us to tell stories about them, much as we tell stories about the people we know in daily life...They give us a feel for people, mingling observable facts with emotional responses."

Crabtree at al, [7] despite disagreeing over the role of Probes with relation to design, also wanted to access participants' lives:

"...our prime concern is informational - a matter of gaining insights into how people live their lives, their everyday circumstances, their routines and rhythms, their practical concerns, and so on." 
Even Urban Probes [26], or “...lightweight provocative urban proto-tasks to inspire direct discussion from people about their current and emerging public urban landscape..." resulted in a visual account of how a particular artefact (in this case a public bin) was interacted with. These "life documents" [27] "take seriously human subjects" [28], gaining personal, human insights into individual biographies

\subsubsection{Making the invisible visible}

The act of participants engaging with Probes involves recording a point-of-view, while 'in-the-moment' and making visible, on one hand, particular actions, places, objects, people etc. and, on the other, wishes, desires, emotions and intentions. Participants can consciously record through taking a photograph, writing something in a diary, speaking into a Dictaphone etc. Alternatively, these momentary interactions may be logged and discussed later in the design process (e.g. [21]). This "enforced visibility' is enabled by an artefact newly introduced into everyday life (e.g. a messaging system - [21]) to inspire “...users and designers to think of new kinds of technologies to support their needs and desires" [21] or a more familiar artefacts (e.g. a scrapbook) to capture aspect(s) of 'undisturbed' everyday life in order or to capture "...the ephemeral and "unsaid"...aspects of intimate exchange..." [34].

\subsubsection{Participant as expert}

"Our emphasis was on using the probes kit to allow the participants [to] collect data about their physical and social context, life style, attitudes, and experiences..." [24]

All Probes are 'participatory' in more than a bland sense. Probes explore, and at times redefine, the investigatorparticipant role. We choose the word 'investigator' carefully because we want to include social scientists, computer scientists, designers etc. The participants themselves take the photos, fill out the diaries, post the postcards and interact with, appropriate, reject what is given to them: "users can become more active contributors instead of being only passive sources of data" [20]. Probes are part of a process of shifting the responsibility for describing situations and lives from the investigator alone to both the participant and the investigator. This approach is not merely, or necessarily, a moral stance on the democratisation of the research process but a reflection on and commitment to the fundamental (methodological) view that people are 'experts' in their own lives.

\subsubsection{Dialogue and conversation}

This feature goes to the heart of how Probes work. Probes start a 'conversation', a dialogue that continues from initially handing over the probes to examining the returns over time. Vetere et al's [34] 'dialogue' concerned intimate acts in stable relationships stretched over a distance:

“...we wanted an approach that allowed us to carry out an ongoing conversation with participants and through this conversation arrive at a shared understanding of intimacy and the place of ICT in mediating intimate acts."

Bill Gaver and his colleagues [14] emphasise Probes as "a kind of gift" [10] and sustaining an ongoing 'conversation' with participants or in the design team:

"Over time, the stories that emerge from the Probes are rich and multilayered, integrating routines with aspirations, appearances with deeper truths."

This dialogue is, then, a way of accomplishing that most difficult, under-rated but essential task: presenting the investigator as human, someone who is trustworthy and who can thereby be trusted with the details of respondents' lives.

\section{THE PROBE DEBATE}

We will now use descriptions of two Probe deployments to examine what issues there have been some disagreement over in the HCI community. We have been privy to both - both the deployments and the disagreements. We will use these cases to: demonstrate that much of the debate around probes is exaggerated (and indeed misplaced); discuss some of the less considered (and perhaps most interesting and challenging) aspects of probes; and to more directly address the question we posed at the beginning of the paper - 'how probes work' - the detail of how they draw out responses from participants and how probe material becomes a resource for designers. The two cases show how Probes interacted in people's lives in quite different ways.

\subsection{Digital Care: Probes as Realisation}

In the description of this deployment we wish to describe the background to the deployment and interpretation of one, very particular probe pack - we present a personal account of a probe pack deployment involving two researchers and one participant. The whole project is described in detail elsewhere (e.g. [3],[4],[5],[7],). The Digital Care project, broadly, was concerned with developing appropriate assistive and enabling technologies across a number of residential care settings: a hostel for former psychiatric patients; a number of elderly people living at home; and a stroke victim and her family. As well as developing appropriate, dependable technology, the project was concerned with the methodological challenges with conducting research in such "sensitive settings". In doing so the work was concerned with design for those typically excluded from the design process - for example, users who are differently abled.

The Probes were deployed in a community care facility supporting ex-psychiatric hospital patients. Two sites formed the community care facility: one site is staffed all the time, even at night, whereas the other is staffed at regular working hours only. A messaging system [5] had been installed at the setting as part of the project supporting communication across the two sites. The messages were logged from October 2002.

The Probe pack described here was more specific than the first deployed at this setting [7] focusing on the communication and use of visual material among staff members and residents. We were interested in finding out about the particular detail of how staff exchanged messages and how they used pictures and photos as part of their everyday work: we wanted them to describe their current practice through the probe packs. We also wanted to explore handing over the designer role to the participants themselves so that they could reflect outside the norm of their current practice and hopefully surprise us with some ideas for technology designs.

Due to the nature of the setting, there were considerable constraints governing data collection. These included concerns over confidentiality and disturbing and alarming the residents through the data collection process - some residents suffered from paranoid schizophrenia and thus the appearance of 'strangers' where they lived could serious interfere with their well-being and care. This sensitivity was indeed a motivation for directing this probe pack towards the health care workers over the residents.

The probe pack comprised: a structured journal booklet; a Polaroid camera with extra film; a disposable camera; PostIt 
notes, glue and pens. The booklet was divided into three parts (a Photo Diary, a Message Book and an Ideas Book). We designed it to be kept like a journal or impressionistic diary capturing the particular as it happened over a week. The instructions in each part had a reflective component in a "Think about" section (e.g. Each day, please think about the following: What message boards and notices you use) and an action component in a "What to do" section (e.g. As you move through each day try to take photos: Of information that has to be made public, perhaps on a notice board).

The Photo Diary was a means for capturing the properties of the environment in which the participants acted and interacted. We oriented it towards understanding what might indeed populate a digital public display if deployed at the setting. The Message Book was a way of enabling participants to reflect on how information was transferred and moved around the setting. Again, we had the deliberate intention of concentrating on what might be suitable for public display content. We directed the instructions towards participants thinking about message transfer at the setting. We intended that The Ideas Book would surface some design ideas. Thus the booklet was designed as a journal and all the materials included were added as support for the construction of a detailed picture describing the role of messages, photographs and pictures in participants' everyday working lives by the participants themselves for the participants themselves. However, there was limited support in the pack for design activities: e.g. only one instruction suggested the use of sketching.

After we collected and reviewed the probe packs we interviewed one participant (Sam), using the probe pack as a prompt. This interview focused on the uses of messages and visuals at one site at the setting only - the semi-independent living facility.

Sam's Photo Diary presented the particular artefacts and information that care-givers used at the setting: notices on the walls (6 photos); visible artefacts such as papers, files, and books (6 photos); people, including residents and staff (5 photos); communication technology such as CCTV, the introduced messaging system, an intercom (5 photos); 'hidden' artefacts used to store important information such as files (4 photos); pictures on the walls ( 2 photos) and a global view of one office (1 photo). Sam's Message book produced 6 entries: PostIt notes containing phone numbers and coding schemes (4); and scraps of paper that were used to transfer information among staff members (2). The content of these messages concerned the recording of medication to be collected, telephone calls to be made and money handed out to residents. Sam had no entries in the Ideas Book.

Some of Sam's returns illustrate that this pack was successful in combating our inability to access particular details of the setting (such as a picture of a filing cabinet containing the resident files "kept by law" not immediately visible to the outsider): they made the invisible visible for us. We also got at in-the-moment action, such as a staff member taking a break from other duties to update daily reports. As well as this we were able to 'observe' particular artefacts 'at work' in the environment and realise their affordances for Sam - PostIt notes as "handy" and "short-term", reports as more permanent, longer term. This was only one aspect of the visibility that the probe pack promoted Sam personally became aware of the importance of making certain things visible and readily available for staff, such as particular telephone numbers.

We also gained insights into the idiosyncrasies of social aspects of this organisation's life - the everyday banter involved in the sharing of a humorous photograph and very ordinary routines, such as going shopping. We got to know Sam's sensitivities and opinions through the Probe pack, accessing the importance of particular artefacts (e.g. PostIt notes) and places (e.g. the main office) s/he experienced for Sam and from Sam's point of view. For example, Sam writing "THE NERVE CENTRE" and taking a photo of the office reflected how important s/he regarded this area as a nexus for message exchange.

This Probe deployment did not seem at all disruptive - instead of challenging and changing behaviour it seemed to tune Sam to his/her current practices and behavior and open a conversation with us about them (which unfortunately did not perpetuate beyond the interview). The reflexivity enforced by the probe pack, instead of embarking Sam on some sort of journey into self, engendered an awareness of action and relationships to others: the amount and importance of information exchanged seemed a genuine, and important, revelation to Sam. Sam was also pleased with the result, noting upon handing over the Probe return, "Well I did my project." The description enclosed in the Probe was also richly (auto)biographical for the investigators.

\subsection{Mediating Intimacy: Probes as Disruption}

In the description of this deployment we wish to describe an experience with one participant couple in The Mediating Intimacy Project ([34],[35],[15]). In this project we worked with six couples in long-term, stable relationships over a sevenweek period. Participants were asked to reflect and report on their use of ICT in their relationship by using a variety of probe pack materials. Reflective tasks included consideration of current practices as well as imagining alterative future practices and associated ICT.

Participants used individual diaries to record daily communicative activities. This included the form of the communication (e.g. SMS, telephone, email etc.) and other details such as the time, date, location, the content and the associated feelings (e.g. urgency, dissatisfaction etc.). The couples also kept a combined scrapbook of their experiences, to record events and express wants, desires, likes and dislikes around these events. They were encouraged to work together on their scrapbooks with pens, crayons, photos, drawings etc. to develop a montage of their intimate lives. A digital camera and printer were provided so they could photograph everyday artefacts and events that expressed important aspects of their interactions. They were encouraged to use these photographs in their scrapbooks. Catchphrase labels (e.g. "I feel alone when..." "I feel supported when...") were provided to help participants write reflectively. Facsimiles of a range of handheld devices were provided midway through the study and participants were asked to use these to imagine future technologies that might support or enhance their relationship. Participants were encouraged to spend 20-30 minutes per day using the probe pack materials, but were assured there was no obligation on their part to do so.

We visited participants four times for contextual interviews during the period of probe deployment. The probe materials produced by participants served as a focus for our interviews. They were literally and figuratively 'on the table' between participants and researchers. The materials were then subject to further interpretation, reflection and discussion in open-ended conversations about the meaning of love, communication, intimacy and sharing a life with another person. These materials positioned in this way enabled a free-flowing and broad-ranging 
discussion that nether-the-less maintained its focus on both participants' experiences and the central research interests of the project.

Danielle and Chris were two of the participants in our study. They were young, married and in their mid-twenties. They were university educated and had professional jobs in the Melbourne central business district. They lived in a small house, in a middle class suburb. They lived a closely connected life. On a typical working day they would wake together, eat breakfast together, catch the train to work together, meet for lunch, catch the train home together and spend the evening together. Even at work, at their separate jobs, they would email and call each other six or seven times a day. On weekends, they spend most of their time together and had little call for using ICTs to communicate with each other.

Day Seven: We have realized through this process of recording our communication that we communicate a lot, about trivial things. It has made us question what we do. We have subconsciously reduced our communication. (Scrapbook entry)

Subsequent to this entry Danielle and Chris had an argument because Chris had not received an SMS message from Danielle. The following entry ensued:

Day Eight: Still not much communication. Only four entries in diary. Is this because we are so conscious of our communication now. The effort of diarising each contact? (Scrapbook entry)

They tell us that several days of ill feeling and fighting followed this event. They were not happy with each other and they were not happy with how they were communicating. Several other communication breakdowns occurred; their lives were less coordinated; their routines were getting out of synch. They resolve their argument, but several other factors were at play making it difficult for them to communicate easily. Chris was at a training course and couldn't be contacted. Danielle was busy at work, and develops an eye ulcer. Constant wedding plans and associated activities exasperated Chris. Frustration gets voiced in the scrapbook and diary. However, when we interview them, things have settled down. The wedding has been and gone. Routines are back in place. Life is as it should be. The scrapbook is full of statements affirming the emotional security they find in being able to reach and converse with each other while apart.

Day 34: Once again we used communications from email to phone to continue conversations previously started - What's Paul Kelly's name? What to get Trev for b'day? Also standard calls. When + what for lunch. Which train home? (Scrapbook entry)

During interviews they told us these stories and what they have learnt during the study. Once they started logging their contacts with each other they were surprised and somewhat taken-aback by the frequency of their calls and emails even if each contact was fleeting and of little consequence on its own. This realization plus the additional effort created by logging all their contacts with each other, led them to call or email each other less. This led to communication breakdowns, and some friction developed in their relationship. This highlighted the importance to their relationship of being in frequent contact. Staying in touch, throughout the day, and sensing the other was readily contactable was worth the cost.

It is tempting to conclude that something akin to the Hawthorne Effect [25] has biased and/or skewed our results: the act of capturing communicative exchanges with scrapbooks and diaries altered those actual exchanges. From a Probes perspective, however, the disruption to Danielle and Chris's lives created by their dedicated engagement generated useful insights. This we regard as one of the beneficial aspects of Probe-type studies and, indeed, mark out how this kind of study differs from other approaches. Despite using materials common to other forms of sociological enquiry, the different manner that participants and researchers engage with those materials is crucial. Probes offer materials for reflection. This reflection, albeit fragmentary, is undertaken by the participants. If their life is disturbed or unsettled, this can bring to the fore the taken-forgranted and help participants to articulate what might otherwise be left unsaid. These reflective fragments in turn, become material fragments for further reflection by researchers or designers, perhaps in the form of writing on Post-it notes and index cards to be shuffled, arranged and subject to further reflective manipulation.

\subsection{What Probes Do}

The two deployments described are quite different: the first was a very targeted probe deployment in a 'sensitive setting' aimed at exploring the content for a public display; the second was an open, investigative deployment aimed at gaining insights into the nature of intimate acts, how these acts are currently supported by the constellation of technologies in people's lives and how they could be supported through future technologies. The first deployment was more functional than the second - a means of making visible the constraints and design possibilities for any public display design. The second deployment was about exploring personal issues that people may be unwilling to talk about with a view to opening a design space to be explored through 'provocative' designs (e.g. Synchromate - [15]). Despite this, certain common themes concerning what probes do, and how probes work, conspicuously emerge.

\subsubsection{Probes humanise}

"They may seem whimsical, but it would be a mistake to dismiss them on that ground: for unless we start to respect the full range of values that make us human, the technologies we build are likely to be dull and uninteresting at best, and dehumanising at worst." [12]

Probes not only generate bland accounts of people's individual lives but intensely personal and sympathetic ones. If we are not careful, in our willingness to theorise (or over-eagerness not to) and, perhaps, in our quest for Sack's "fantastic new communication machine" [29], the individual dies, the human gets mummified in raft of facts and models, numbers and statistical explanations, sketches and prototypes, claims about order and ordinariness. Probes cannot help but avoid this, partly because they are (sometimes) quite difficult to make sense of and partly because individual people who we get to know and sympathise with produce them and pass them to us to fathom.

\subsubsection{Probes create fragments}

"Rather than producing lists of facts about our volunteers, the Probes encouraged us to tell stories about them, much as well tell stories about the people we know in daily life." [14]

In both deployments Probes were chosen less because of any single methodological commitment than due to the nature of the research setting and question and the constraints and difficulties each posed. Fragmentary data is a real concern in settings such as the home, where access and capture are concerns. Across both settings we have presented here, the returns were, in a very important sense incomplete and 'fragmentary', but far from trivial: making important telephone numbers visible in the kind of environment that Sam worked in is a critical concern; SMS 
services being reliable for dislocated intimates is important for sustaining a connection, albeit asynchronous. These, often very specific and personal, fragments acted as a starting point for discussion in interviews, an impetus for us to start telling stories about their lives: the 'whimsical' became a resource for design.

\subsubsection{Probes use uncertainty}

"Perhaps most important is that I deeply value the undermining of certainty we achieve with our probes. I also value the subversion of understood researcher-researchee relations.... we actively enjoy confusion and strangeness and most researchers aren't very comfortable with these qualities." [Gaver, personal communication]

This is an observation drawn from our experience with many probe deployments. Participants are never really sure what to do, no matter how specific the instructions might be, although the degree of uncertainty may vary. Even minimally designed Technology Probes or Mobile probes require some 'working out'. And we believe Gaver is right - this uncertainty is a good thing, but not necessarily, or only, in the way he describes it. We believe, the 'working out' that Probes enforce (between the researchers and the researched), their "ambiguity" and "strangeness" forces participants to make something of them through fitting them into their lives (or not), and to respond to them and gain a new perspective through that response. In Sam's case it concerned the number of messages that circulated in the workplace, in Danielle and Chris's it concerned the frequency of their communication. In both deployments we believe participants engaged in the process through negotiating this uncertainty. It became their 'project', much like homework or an assignment. This commitment to the process is exceptionally important and it cultivated prolonged engagement with participants in The Intimacy Project.

\subsubsection{Probes inspire}

"Our intention - and our brief - in this project was not to tackle the Bijlmer's apparent problems directly, nor to produce a public art work that merely comments on the situation. Instead, our primary concern has been to find new ways that technology can enter and affect everyday culture... This emphasis on offering new opportunities through design rather than solving problems underlies much of what we do and how we do it." [9]

Both Probe deployments had implications for design. The directness of the mapping between the probe returns and the designs can vary, but both inspired designs and we can relate and describe how they inspired. For example, Sam taking a photo of a set of telephone numbers, printed out and stuck on the wall showed us the importance of certain information being permanent, visible and readily available on any digital display. The habit that Danielle and Chris had of making calls and sending emails to discuss trivial matters showed us the importance of communication for 'staying in touch' as opposed to exchanging key information, making decisions etc. This insight was conducive to arriving at the notion of "phatic technologies" - technologies where the design emphasis is on connection rather than informational exchanges [15].

Thus in both projects it may be difficult to trace the path between Probe returns and any resulting designs but the act of using the data is certainly accountable, despite its use within creative design being indirect.

\subsubsection{Probes engender interpretation}

"By producing returns that reverberate with mutual influence, it is impossible to arrive at comfortable conclusions about our volunteers' lives or to stand back and regard them dispassionately. Instead, we are forced into a situation that calls for our own subjective interpretations." [14].

In the two deployments the probe returns were obviously 'interpreted' by the project teams. Of course they were, but we are using a relatively weak notion of 'interpretation' here and trying to avoid the common problem of reading too much into other people's lives. In the first deployment, parts of the Probe formed the basis for further questioning. In the second deployment, a model of intimacy was produced. Still other probe deployments have resulted in descriptive models of constituent themes (e.g. [34]). Thus Probes, in both deployments supported the interpretation of participants' lives, albeit an interpretation that was represented differently (i.e. in the form of questions, in a figure). In this sense the issue is less about 'interpretation' than involvement, with empathy, with recognition of lives made 'accountable' through the probes.

\subsubsection{Probes provoke... a little}

"The experimental and subversive nature of the original probes is often lost, however, when they are seen as a reproducible method and explained within traditional accounts of knowledge production in user-centered design." [1]

Gaver and his colleagues [10], in an oft-neglected sidebar, describe how Cultural Probes, also draw on the Situationalists, both conceptually and methodologically, through embracing the importance of functional aesthetics and the use of psychogeographical maps and collages. In doing so society's naive consumption of its own experience is supposedly challenged and new perspectives on everyday life are supposedly provoked.

Clearly, some probes provoke more than others. Asking people to take photos of their surroundings may well be less provocative than asking them to describe a lucid dream though this may not always be the case. The provocative and subversive nature of Probes is probably overstated. All probes provoke some kind of reaction, they provoke people into examining that which they frequently take for granted - their own lives. How useful such provocation might be for design purposes is debateable. 'Provocative' designs are often constrained by very ordinary things - by the skills of the design team, by the funding available, by the nature of the setting and so on. The reality is that designs emerging from or as part of Probes have a limited audience and a short-term deployment. Probes, however, do enforce reflexivity which is important when considering why they work.

\subsection{Reframing the Debate}

"I like the possibility that people's responses include their aspirations and fears as well as their lived realities, and that they might lie to us or leave out stuff, and that's all explicitly understood and accepted and fair. I like that the probes reveal us as much as the people we give them to. I like that they are playful and rewarding, so we aren't just taking from volunteers but giving to them as well. There's probably more, but that's the gist." [Gaver, personal communication]

We have presented evidence that shows that Probes 'work' as interpretative material because they enforce a 'working out' between the researched and the investigated, a joint and effortful enterprise with participants, and not simply a series of epiphanies. We think the Probes provide us with some useful and interesting forms of access to this commonsense understanding of the organisation of the world, thereby beginning a conversation that permits us to probe more deeply 
into people's lives whilst reassuring the 'subjects' of our research that we are ordinary, harmless, (if strange) people.

In a similar, and related, fashion we suggest that Probe materials encourage various forms of 'reflexivity' both in the standard social science sense of reflection or contemplation and in the more precise, if more mundane, ethnomethodological sense of making actions accountable (as the actions they observably are) [33]. In following the various suggestions in the Probe pack, participants embark on a journey of 'instructed actions' [8] - putting their lives together - but where the instructions and outcomes were never entirely clear and where the onus is on the participants to make their instructed action (i.e. what they have to do for their "project") accountable, reflexive, workable action.

This outcome has been framed as the value of uncertainty, which it undoubtedly is, but it also is an approach that places this 'working out' at the heart of an ongoing design process. The idea of Probes involving serious, effortful accomplishment, rather than being a mere distribution and collection exercise, resonates with other methodological issues concerning how we go about tapping into other peoples' lives. In "The Demise of the Native", a critique of common methodological stances on culture, Sharrock and Anderson [31] point, inadvertently, to some of these other methodological issues that Probes, sensitively used, might address. In particular they suggest that the idea of a 'culture', that a Probe might unearth as some kind of input to design, the idea of a shared set of meanings and understandings that thereby inform our design endeavour, should be the endpoint, the product of the analysis, what it seeks to demonstrate, the end product of serious and sustained enquiry and not what enquiry is all too simplistically predicated upon. In completing the probe packs our respondents uncover and reveal their 'culture', they put their culture on display, aspects of their everyday lives, but not just to us, but to themselves: it is enquired into and 'discovered' by them as much as by researchers and designers. This is why the notion of the probes as beginning a dialogue is so important. Similarly we believe we have shown Probe materials are never simply translated or transformed into design recommendations or 'requirements' - if anyone ever believed this - and thus we believe that Bill Gaver and his colleagues are right: Probes support designers through the iterative and "provisional" [14] storytelling within design teams. Who are these people? What are they like? That is how they become a resource for design.

We also make the overall observation that arguments concerning the difference between Probes acting as 'inspiration' and 'information' arise from:

- cloaking design in mystery when it is, like anything else, an everyday practice;

- a lack of acknowledgement that both design work and interpretative work are 'accountable' [8];

- different 'vocabularies' and practices across engineering, design and social science;

- a view of 'design work' that is not truly interdisciplinary that 'design' belongs to designers and not anyone else.

We believe a real strength of probes is that they support interdisciplinary iterative interpretative and design work where stories are generated, renewed and reworked over time. These are used to inform or inspire - whatever word you want to choose - designs that are at once provocative and traceable to the same stories circulating in design teams.

\section{CONCLUSION: 'THE TURN TO PROBES'}

This paper was originally entitled: "All That You Wanted to Know About 'Probes' and Were Too Afraid to Ask" - as a (strange) homage to the Woody Allen film, 'Everything You Always Wanted to Know About Sex But Were Afraid to Ask' and the promise it supposedly held, because we were intent on exploring the real issues with probes and their inherent 'dirtiness' when engaged with properly: the issue, for us is to understand exactly how they work. While writing that particular paper, Boehner and her colleagues 'interpreted the probes' [1] Then it seemed important to ask if Probes some form of 'departure' or if they are simply old methods (and even methodologies) repackaged and to an audience hungry to consume the next trend. Our contention is that Probes are an amalgam of existing social science methods - photography, life documents, biographical interviews, and structured diarizing and that HCI has done what it always has with methods: borrowed and adapted them. However, we also believe, a belief that we hope is borne out by the particular data about particular people presented in this paper, that Probes mark a turn to the personal in $\mathrm{HCI}$ and indicate a need for methods that reflect the individual's everyday life in design responses, the need to get beyond the antiseptic general.

Some of the future challenges for Probes are both practical and methodological. They are simply a lot of work for participants (one of our participants noted: "You didn't tell me you were going to give me homework!') and often have low return rates as with the first case presented here. They can also, as illustrated in the second case, disrupt the everyday practices of participants through enforcing an awareness and visibility of action previously absent. We believe variants of Technology Probes and Mobile Probes have the greatest potential for addressing the first concern and approaches embracing the playfulness of Probes (e.g. [34]'s 'magic boxes'). We also believe that the 'disruption' that Probes can bring, rather than being a concern, if responsibly addressed, may well be a strength: this 'disruption' is part of the 'working out' of how technology is and may be used in participants' lives and how any new technology might affect them. Thus longitudinal probe use involving different variants of Probes to support this ongoing 'conversation' and 'working out' seems to offer the most promise here in addressing this concern.

We hope this paper has reoriented the discussion around Probes away from what they might mean to their 'dirtiness', what they $d o$ and how they work; because such mundane (if sordid) detail seems important to consider as Probes continue to develop. The directions that Probes are taking tell us much about them (and those who use them). These 'new' Probes fuse different Probe variants and leverage the strengths of each. For example, some of the authors have combined Technology Probes with Cultural Probes through 'magic boxes' [34]. These cardboard gift boxes exchanged between grandparents and grandchildren provide insights into how playful activities across generations could be supported by technology. Other possibilities concern combining Technology Probes and Mobile Probes through the use of mobile blogs to access the everyday activities of individuals as they move, communicate and share. These converged Probes leverage: the personal nature of digital artefacts and their particular form factor; how personal digital artefacts are embedded in people's lives as they traverse through them and; the generated typographies and topologies of 'living digitally' in the form of captured and ever increasing number of 
accountable digital transactions and interactions (e.g. Web browser histories, text messages, files generated on-the-fly).

Such probes offer to bridge qualitative and quantitative approaches to research and take seriously new technologies both being embedded in everyday life and being generative of digital content that is consumed by others - an anonymous public in the case of many blogs and friends and family in the case of protected digital photo-sharing. They also challenge old roles and approaches: 'traditional' research methods have historically been divorced from everyday life. How do we respond when everyday life is being sustained and even lived through what we are researching? How do we approach analysis and when personal data generation is continual and almost effortless? How do we interpret disparate data distributed across time and place?

\section{ACKNOWLEDGMENTS}

This research was supported by a Microsoft European Research Fellowship (Social Interaction and Mundane Technologies), the EPSRC funded PLATFORM: Social Analysis in Systems Engineering project (grant ref: R97726/01), the EPSRC funded CASIDE project (grant ref: EP/C005589) and a Nokia University Donation (Mobile Phones as Probes, Props and Prototypes For Life Change). Special thanks to Bill Gaver for his comments and to our participants for their involvement in the research

\section{REFERENCES}

[1] Boehner. K, Vertesi, J, Sengers, P \& Dourish P. How HCI interprets the Probes. In Proc. CHI 2007, ACM Press, New York, 1077-1086,

[2] Brown, B. A. T., Sellen A. J. and O'Hara K. P. A diary study of information capture in working life. In Proc. CHI 2000, ACM Press, New York, 438-445.

[3] Cheverst, K. Cobb, S., Hemmings, T, Kember, S., Mitchell, K., Phillips, P., Procter, R., Rodden T. and Rouncefield, M. Design with care. Journal of New Technology in the Human Services, 14, 1 (2001), 39-47

[4] Cheverst, K., Fitton, D., Rouncefield, M. \& Graham, C. 'Smart Mobs' and Technology Probes: Evaluating Texting at Work. In Proc. ECITE 2004, Royal Netherlands Academy of Arts and Sciences, Amsterdam, 73-80.

[5] Cheverst, K., Dix, A., Fitton, D., Rouncefeld, M., and Graham, C. Exploring Awareness Related Messaging through Two Situated Display based Systems. Human-Computer Interaction, 22, 1 (2007), 173-220.

[6] Crabtree, A. Designing Collaborative Systems: A Practical Guide to Ethnography, Springer-Verlag, London, 2003.

[7] Crabtree, A., Hemmings, T., Rodden, T., Cheverst, K., Clarke, K., Dewsbury, G., Hughes, J., Rouncefield, M., (2003b). Designing With Care: Adapting Cultural Probes to Inform Design in Sensitive Settings. In Proc. OzCHI 2004, 4-13. Brisbane, Australia: Ergonomics Society of Australia

[8] Garfinkel, H. Studies in Ethnomethodology, Prentice-Hall, Englewood Cliffs, New Jersey, 1967.

[9] Gaver, W. and Dunne, A. (1999a). Projected Realities: Conceptual Design for Cultural Effect. In Proc. CHI 1999, ACM Press, New York, 600-607

[10] Gaver, W., Dunne, A., Pacenti, E.. Design: Cultural Probes. Interactions: New Visions of Human-Computer Interaction, 6, 1, (1999b), 21-29.

[11] Gaver, W.H., Hooker, B. and Dunne, A. The Presence Project, Department of Interaction Design, London, 1999c.
[12] Gaver, W. Designing for ludic aspects of everyday life. ERCIM News, No.47. Available from: http://www.ercim.org/publication/Ercim_News/enw47/gaver. html, (2001)

[13] Gaver, W. Designing for Homo Ludens. I3 Magazine 12 (June 2002)

[14] Gaver, W., Boucher, A., Pennington, S., and Walker, B (2004). Cultural probes and the value of uncertainty. Interactions: New Visions of Human-Computer Interaction, $11,5,(2004), 53-56$

[15] Gibbs, M., Vetere, F., Howard, S., and Bunyan, M. (2005) SynchroMate: A Phatic Technology for Mediating Intimacy. In Proc. DUX 2005, AIGA, New York, 37.

[16] Graham, C, Cheverst K, Fitton D, \& Rouncefield M. "How Do You Turn A Duck Into A Soul Singer? Put It In The Microwave Until Its Bill Withers": Some social features of a simple technology. In Proc. of the Less Is More Conference 2005, Microsoft, Cambridge.

[17] Grudin, J. Why CSCW applications fail: problems in the design and evaluation of organizational interfaces. In Proc. CSCW 1988, ACM Press, New York, 85-93.

[18] Horst, W., Bunt, T., Wensveen, S., and Cherian, L. (2004). Designing Probes for Empathy with Families. In Proc. of Dutch Directions in HCI 2004, ACM Press, New York.

[19] Hughes, J., King, V., Rodden, T., Andersen, H. (1994). Moving out of the control room: ethnography in system design. In Proc. CSCW 1994, ACM Press, New York, 429438.

[20] Hulkko, S., Mattelmäki, T.; Virtanen, K. and Keinonen, T., Mobile Probes. In Proc. NordiCHI 2004, ACM Press: Tampere, Finland.

[21] Hutchinson, H., Mackay, W., Westerlund, B., Bederson, B.B, Druin, A., Plaisant, C., Beaudouin-Lafon, M., Conversy, S., Evans, H., Hansen, H., Roussel, N. and Eiderbäck, B. Technology probes: Inspiring Design for and with Families. In Proc. CHI 2003, ACM Press, New York, 17-24.

[22] Kjeldskov, J., Gibbs, M., Vetere, F., Howard, S., Pedell, S., Mecoles, K., Bunyan, M. 2005, Using Cultural Probes to Explore Mediated Intimacy. Australian Journal of Information Systems, 12, 1 (2005), 102-115.

[23] Löwgren, J. (1995). Applying design methodology to software development. In Proc. DIS 1995, ACM Press, New York, 8795 .

[24] Mattelmäki, T. \& Battarbee, K. Empathy Probes. In Proc. Participatory Design Conference 2002, CPSR, Palo Alto, CA, 266-271

[25] Mayo, E. The Human Problems of an Industrial Civilization, New York: MacMillan, 1933.

[26] Paulos, E. and Jenkins, T. Urban probes: encountering our emerging urban atmospheres. In Proc. CHI 2005, ACM Press, New York, 341-350

[27] Plummer, K. Documents of Life. George Allen \& Unwin, London, 1983.

[28] Plummer, K. Documents of Life 2: An Invitation to a Critical Humanism, Sage Publications, London, 2001.

[29] Sacks, H. A single instance of a phone-call opening. In Jefferson, G. (ed) Lectures on Conversation Volume II. Blackwell, Oxford, 1992, 542-553.

[30] Schutz, A. The Phenomenology of the Social World. Northwestern University Press: Evanston, Illinois, 1967. 
[31] Sharrock, W. and Anderson, R. On The Demise of the Native: Some Observations on and a Proposal for Ethnography. Human Studies (5), (1982), 119-135.

[32] Shelley, M. Frankenstein. Penguin Books, Harmondsworth, 1985.

[33] Slack, R. S. Reflexivity or Sociological Practice: A Reply to May. Sociological Research Online, 5, 1 (2000). Available from: http://www.socresonline.org.uk/5/1/slack.html

[34] Vetere, F., Martin R. Gibbs, Kjeldskov, J., Howard S., Mueller, F., Pedell, S., Mecoles, K., and Bunyan, M.

Mediating intimacy: designing technologies to support strongtie relationships. In Proc. CHI 2005, ACM Press, New York, $471-48$.
[35] Vetere, F., Davis, H., Gibbs, M., Francis, P., and Howard, S. A Magic Box for Understanding Intergenerational Play. In Proc. CHI 2006, ACM Press, New York, 1475-1480.

[36] Vetting Wolf, T., Rode, J.A., Sussman, J. and Kellogg, W.A. (2006). Dispelling Design as the 'Black Art'. In Proc. CHI 2006, ACM Press, New York, 521-530.

[37] Wenger, E. Communities of Practice: Learning, Meaning and Identity. Cambridge University Press, Cambridge, 1988.

[38] Wittgenstein, Ludwig. Philosophical Investigations. Blackwell Publishing, 1953/2001. 